Supporting Information

\title{
Facile synthesis of a library of hollow metallic particles through galvanic replacement of liquid gallium
}

Aleksandra S. Falchevskaya, Artur Y. Prilepskii, Sofia A. Tsvetikova, Elena I. Koshel and Vladimir V.

Vinogradov*.

ITMO University, International Institute "Solution Chemistry of Advanced Materials and

Technologies” (SCAMT) 9, Lomonosova str., Saint Petersburg, 191002, Russian Federation

Table S1. General synthetic methods for bimetallic capsules.

\begin{tabular}{|c|c|c|c|c|c|c|}
\hline Salt & Designation & $\begin{array}{l}\mathrm{Ga}: \mathrm{Me}^{\mathrm{n}+} \\
\text { molarratio }\end{array}$ & $\begin{array}{c}\mathrm{C}_{\mathrm{Me}}^{\mathrm{nt}} \\
{[\mathrm{M}]}\end{array}$ & $\begin{array}{l}\text { Reaction } \\
\text { time }[\mathrm{min}]\end{array}$ & Special conditions & $\begin{array}{c}\text { Final Ga:Me } \\
\text { ratio }\end{array}$ \\
\hline $\mathrm{CuSO}_{4}$ & $\mathrm{Ga}-\mathrm{Cu}-1$ & $1: 1$ & 0.036 & 60 & - & $21: 1-8: 1$ \\
\hline $\mathrm{Cu}(\mathrm{Ac})_{2}$ & $\mathrm{Ga}-\mathrm{Cu}-2$ & $1: 1$ & 0.036 & 120 & - & $3.6: 1$ \\
\hline $\mathrm{Cu}(\mathrm{Ac})_{2}$ & $\mathrm{Ga}-\mathrm{Cu}-2-\mathrm{CTAB}$ & $1: 1$ & 0.036 & 120 & $\begin{array}{c}\text { Addition of CTAB (1-2\% } \\
\text { wt.) }\end{array}$ & $1.8: 1$ \\
\hline $\mathrm{Cu}(\mathrm{Ac})_{2}$ & $\mathrm{Ca}-\mathrm{Cu}-2^{\prime}$ & $1: 1$ & $\begin{array}{c}0.036+ \\
0.036\end{array}$ & $90+90$ & $\begin{array}{c}\text { The reaction was performed } \\
\text { in two steps, separated by } \\
\text { washing }\end{array}$ & $\begin{array}{l}3.6: 1- \\
2.1: 1\end{array}$ \\
\hline $\mathrm{Cu}(\mathrm{Ac})_{2}$ & Ga-Cu-2-PEI & $1: 1$ & 0.1 & 90 & $\begin{array}{c}\text { Polyethyleneimine: } \mathrm{Cu}^{2+}= \\
0.5: 1 \text { (molar ratio) }\end{array}$ & $\begin{array}{l}\text { 15:1-full } \\
\text { conversion } \\
\text { into } \mathrm{Cu}\end{array}$ \\
\hline $\mathrm{NiCl}_{2}$ & & $1: 1$ & $0.05-0.1$ & $60-1440$ & - & No more then \\
\hline $\mathrm{Ni}\left(\mathrm{NO}_{3}\right)_{2}$ & & & & & & $240: 1$ \\
\hline $\mathrm{Ni}(\mathrm{Ac})_{2}$ & Ga-Ni-1 & $1: 1.5$ & 0.125 & 60 & - & $1.6: 1$ \\
\hline$\left[\mathrm{Ni}\left(\mathrm{NH}_{3}\right)_{6}\right] \mathrm{Cl}_{2}$ & Ga-Ni-2 & $3.45: 1$ & 0.0035 & 20 & - & $1: 2.2$ \\
\hline$\left[\mathrm{Co}\left(\mathrm{NH}_{3}\right)_{6}\right] \mathrm{Cl}_{2}$ & Ga-Co & $3.45: 1$ & 0.0035 & 10 & - & $1: 3.67$ \\
\hline$\left[\mathrm{Cd}\left(\mathrm{NH}_{3}\right)_{4}\right]\left(\mathrm{NO}_{3}\right)_{2}$ & $\mathrm{Ga}-\mathrm{Cd}$ & $3.45: 1$ & 0.0035 & 30 & - & $5: 1$ \\
\hline$\left[\mathrm{Cu}\left(\mathrm{NH}_{3}\right)_{6}\right] \mathrm{SO}_{4}$ & & $3.45: 1$ & 0.0033 & 5 & - & $1: 14$ \\
\hline $\mathrm{SnCl}_{2}$ & $\mathrm{Ga}-\mathrm{Sn}$ & $0.5: 1$ & 0.12 & 30 & $\begin{array}{l}\text { Salt was dissolved in excess } \\
\text { of } \mathrm{HCl}\end{array}$ & $1: 9$ \\
\hline $\mathrm{SnCl}_{2}$ & $\mathrm{Ga}-\mathrm{Sn}$ & $1: 1$ & 0.01 & 240 & $\begin{array}{l}\text { Salt was dissolved in excess } \\
\text { of } \mathrm{HCl}\end{array}$ & $\begin{array}{l}\text { Full } \\
\text { conversion } \\
\text { into } \mathrm{Sn}\end{array}$ \\
\hline
\end{tabular}

Table S2. Effect of precursors on wall thickness

\begin{tabular}{|c|c|c|c|c|c|c|}
\hline Salt & $\begin{array}{c}\text { Sample } \\
\text { name }\end{array}$ & $\begin{array}{c}\mathrm{C}_{\mathrm{Me}^{\mathrm{n}+}} \\
{[\mathrm{M}]} \\
\end{array}$ & $\begin{array}{c}\text { Time } \\
\text { [hours] }\end{array}$ & $\begin{array}{c}\text { Initial } \\
\mathrm{Ga}: \mathrm{Cu}^{2+} \text { ratio }\end{array}$ & $\begin{array}{c}\text { Wall thickness } \\
{[\mathrm{nm}]}\end{array}$ & $\begin{array}{c}\text { Inner volume } \\
{\left[\mu \mathrm{m}^{3}\right]}\end{array}$ \\
\hline \multirow{3}{*}{$\mathrm{CuSO}_{4}$} & A1 & 0.1 & 0.5 & $1: 1$ & 135 & 186.6 \\
\hline & A2 & 0.05 & 0.5 & $1: 1$ & 162 & 67.3 \\
\hline & A3 & 0.05 & 0.5 & $2: 1$ & 68 & 1825.7 \\
\hline \multirow{3}{*}{$\begin{array}{c}\mathrm{Cu}(\mathrm{Ac})_{2}-\mathrm{PEI} \\
(1: 0.5)\end{array}$} & B1 & 0.01 & 1.5 & $1: 1$ & 108 & 1.8 \\
\hline & B2 & 0.02 & 0.5 & $1: 1$ & 73 & 3.8 \\
\hline & B3 & 0.01 & 1 & $1: 1$ & 32 & 27.1 \\
\hline \multirow{3}{*}{$\mathrm{Ni}(\mathrm{Ac})_{2}$} & $\mathrm{C} 1$ & 0.1 & 1 & $1: 2$ & 403 & 130.6 \\
\hline & $\mathrm{C} 2$ & 0.05 & 4 & $1: 1$ & 330 & 52.6 \\
\hline & C3 & 0.04 & 2 & $1: 1$ & 467 & 91.3 \\
\hline
\end{tabular}


Table S3. $\mathrm{N}_{2}$ adsorption-desorption data

\begin{tabular}{cccc}
\hline Sample & Surface area $\left[\mathrm{m}^{2} / \mathrm{g}\right]^{\mathrm{a})}$ & Pore volume $\left[\mathrm{cm}^{3} / \mathrm{g}\right]$ & Pore size $[\mathrm{nm}]^{\mathrm{b})}$ \\
\hline Ga & 3 & 0.007 & 3.9 \\
Ga-Ni-1 & 20 & 0.038 & 3.9 \\
Ga-Cu-1 & 12 & 0.021 & 3.2 \\
Ga-Cu-2 & 28 & 0.022 & 3.5 \\
\hline
\end{tabular}

${ }^{\text {a) }}$ Specific surface area data calculated from multi-point BET method; ${ }^{\text {b) }}$ Pore size estimated from the desorption isotherm by the BJH model

Table S4. GRR effectiveness at different temperatures in terms of $\mathrm{Ga}: \mathrm{Cu}$ ratio in $\mathrm{Ga}-\mathrm{Cu}$ samples

\begin{tabular}{ccc}
\hline Sample & Temperature $\left[{ }^{\circ} \mathrm{C}\right]$ & Ga:Cu ratio \\
\hline Ga-Cu-1 & 20 & $1: 0.12$ \\
Ga-Cu-1 & 10 & no copper detected \\
Ga-Cu-1 & 5 & no copper detected \\
Ga-Cu-2 & 20 & $1: 0.3$ \\
Ga-Cu-2 & 10 & $1: 0.11$ \\
Ga-Cu-2 & 5 & $1: 0.09$ \\
\hline
\end{tabular}



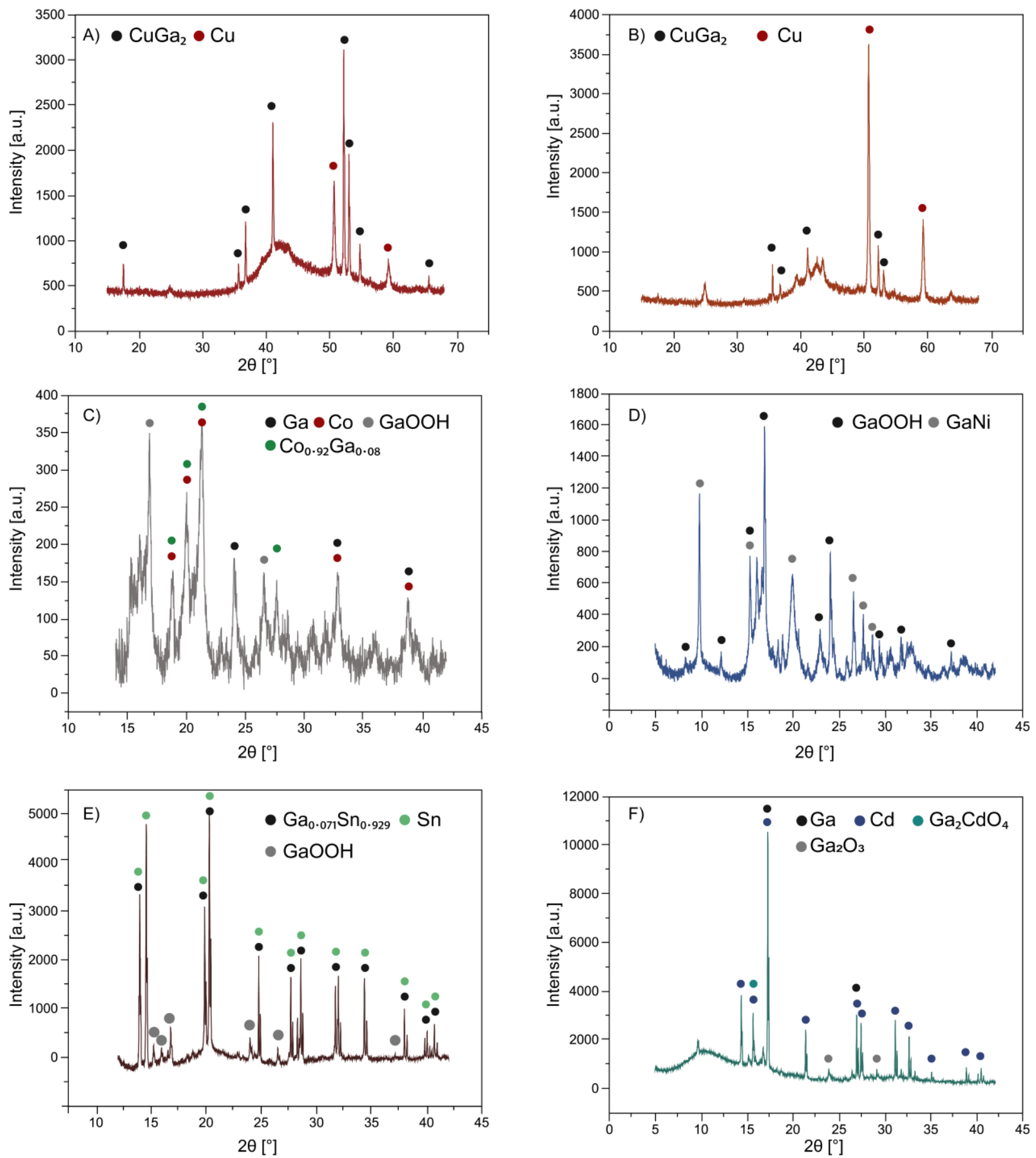

Figure S1. X-ray diffraction data obtained after GRR of Ga particles with: a) $\left.\left.\left.\mathrm{Cu}\left(\mathrm{NO}_{3}\right)_{2} ; \mathrm{b}\right) \mathrm{Cu}(\mathrm{Ac})_{2} ; \mathrm{c}\right)\left[\mathrm{Co}\left(\mathrm{NH}_{3}\right)_{6}\right] \mathrm{Cl}_{2} ; \mathrm{d}\right)$ $\left.\left.\left[\mathrm{Ni}\left(\mathrm{NH}_{3}\right)_{6}\right] \mathrm{Cl}_{2} ; \mathrm{e}\right) \mathrm{SnCl}_{2} ; \mathrm{f}\right)\left[\mathrm{Cd}\left(\mathrm{NH}_{3}\right)_{4}\right]\left(\mathrm{NO}_{3}\right)_{2}$ 
a.
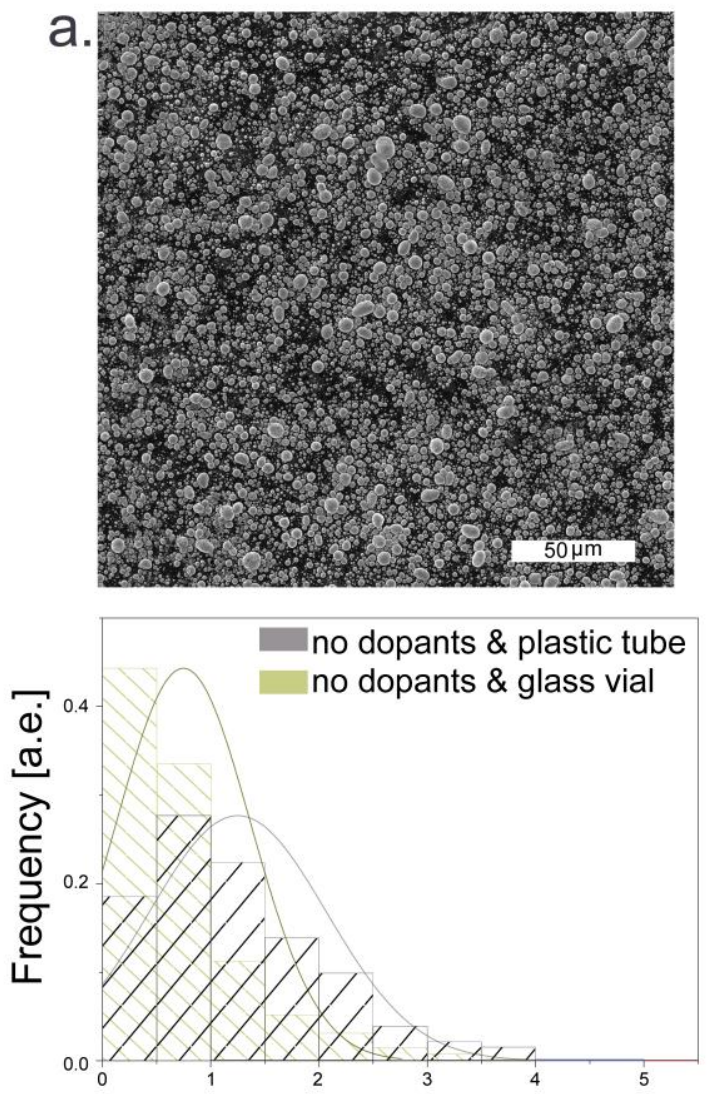

Diameter $[\mu \mathrm{m}]$

C.
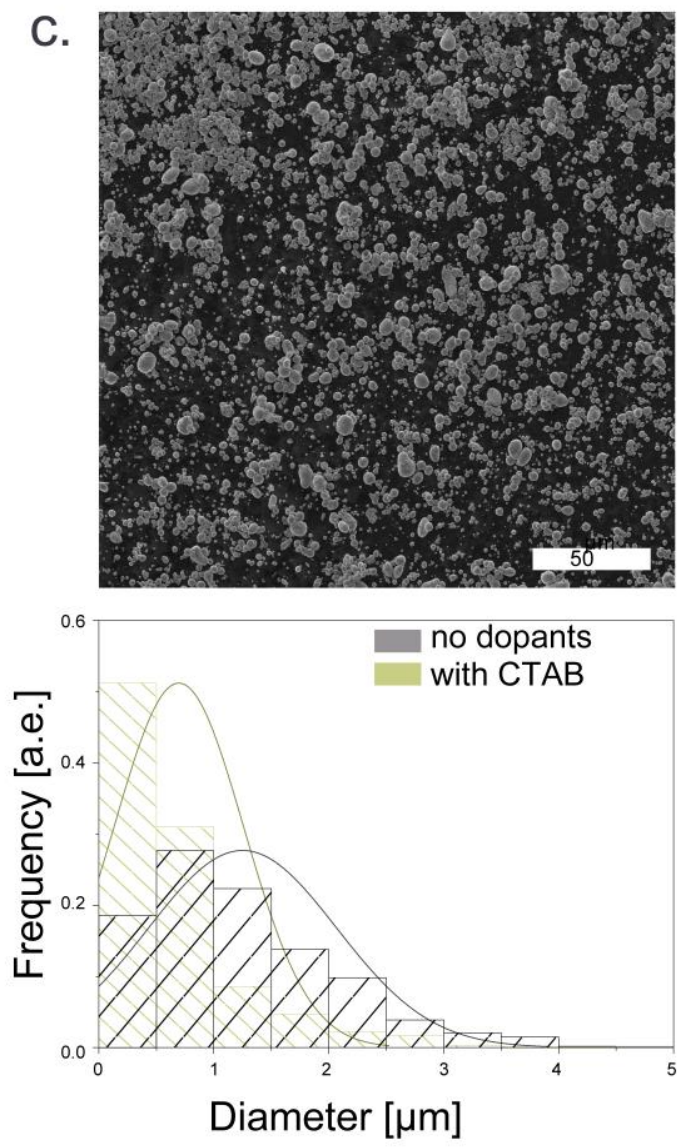

b.
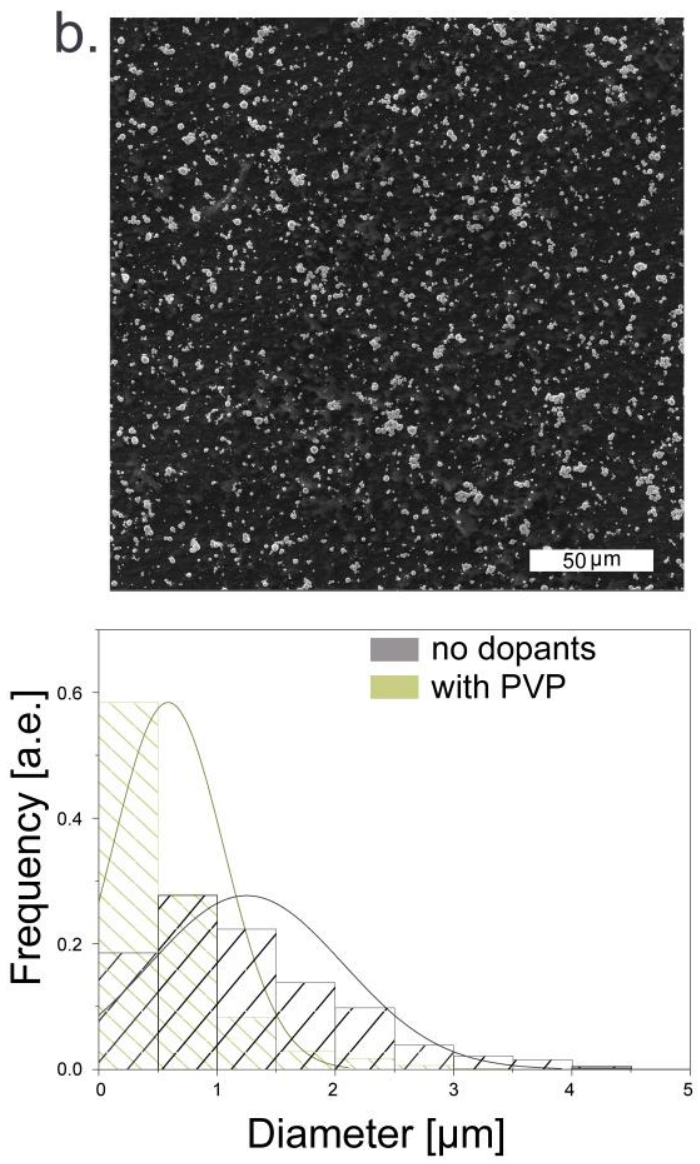

d.
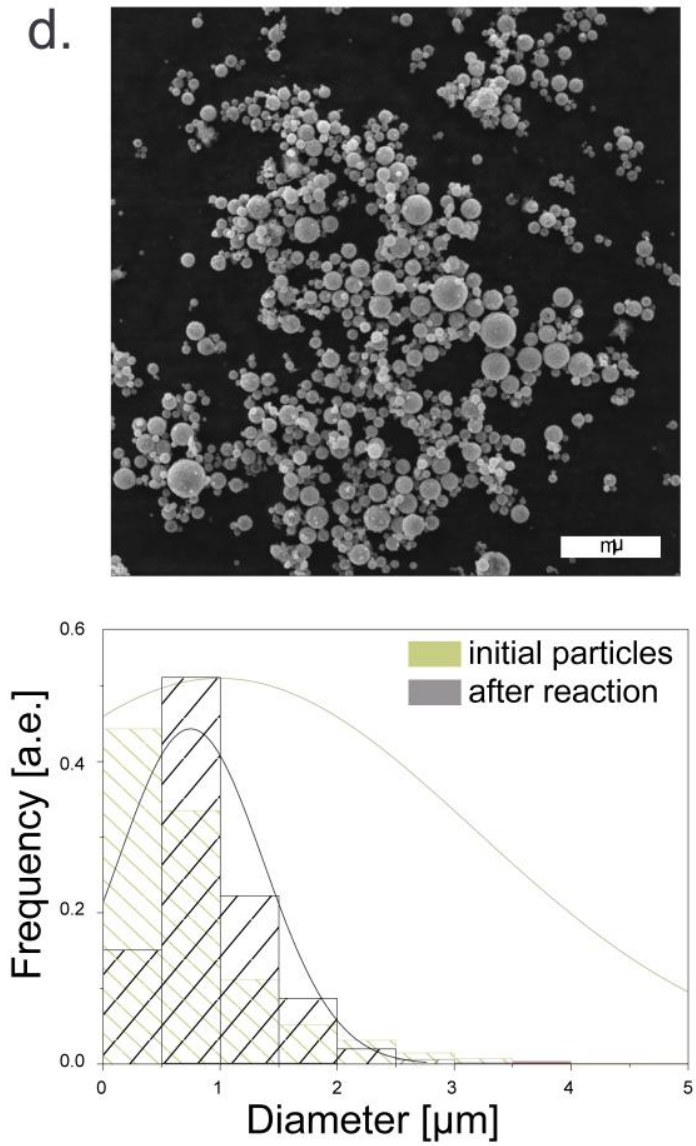

S2. Size distribution and the corresponding SEM images of liquid gallium particles. a) Liquid gallium particles obtained w surfactants in a glass vial; b) liquid gallium particles obtained in a glass vial with the addition of PVP; $c$ ) liquid gallium particles obtained in a glass vial with the addition of CTAB (1-2\%wt); d) Ga-Cu-2-PEI capsules synthesized from the sample shown on (a) image 

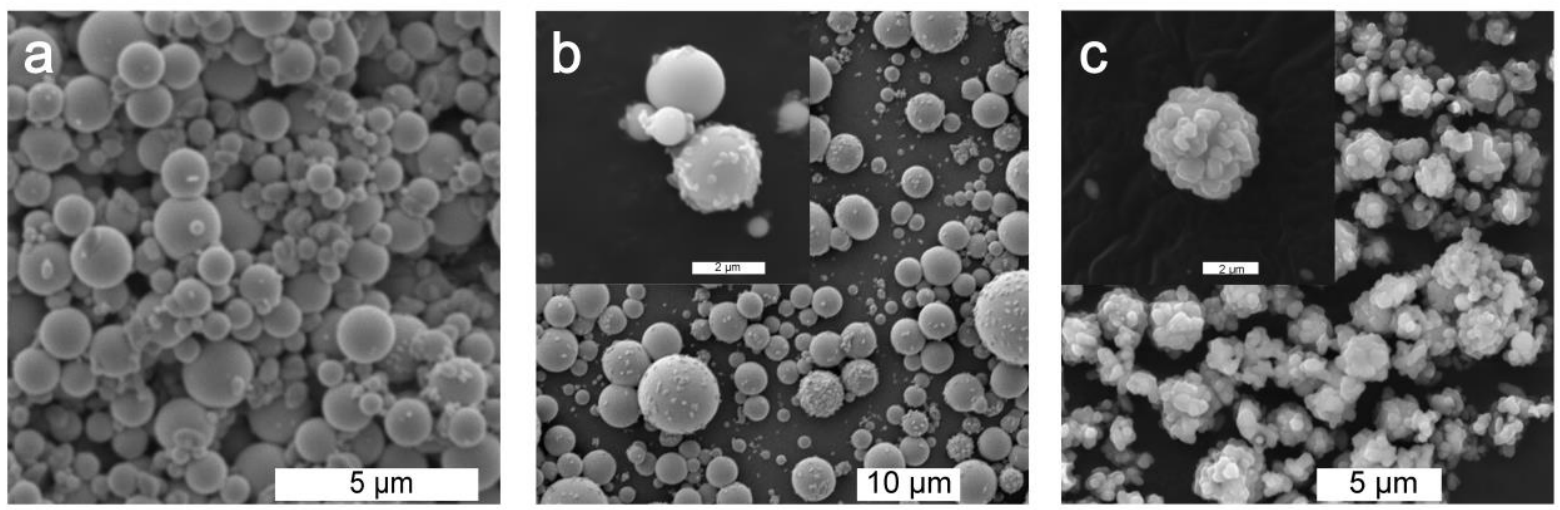

Figure S3. Oxidation of Ga particles over time in aqueous solution with the formation of GaOOH: a) freshly prepared Ga particles; b) Ga particles after 24 hours of incubation in aqueous solution; b) Ga particles after 7 days of incubation in aqueous solution. No surfactants or stabilizers were added

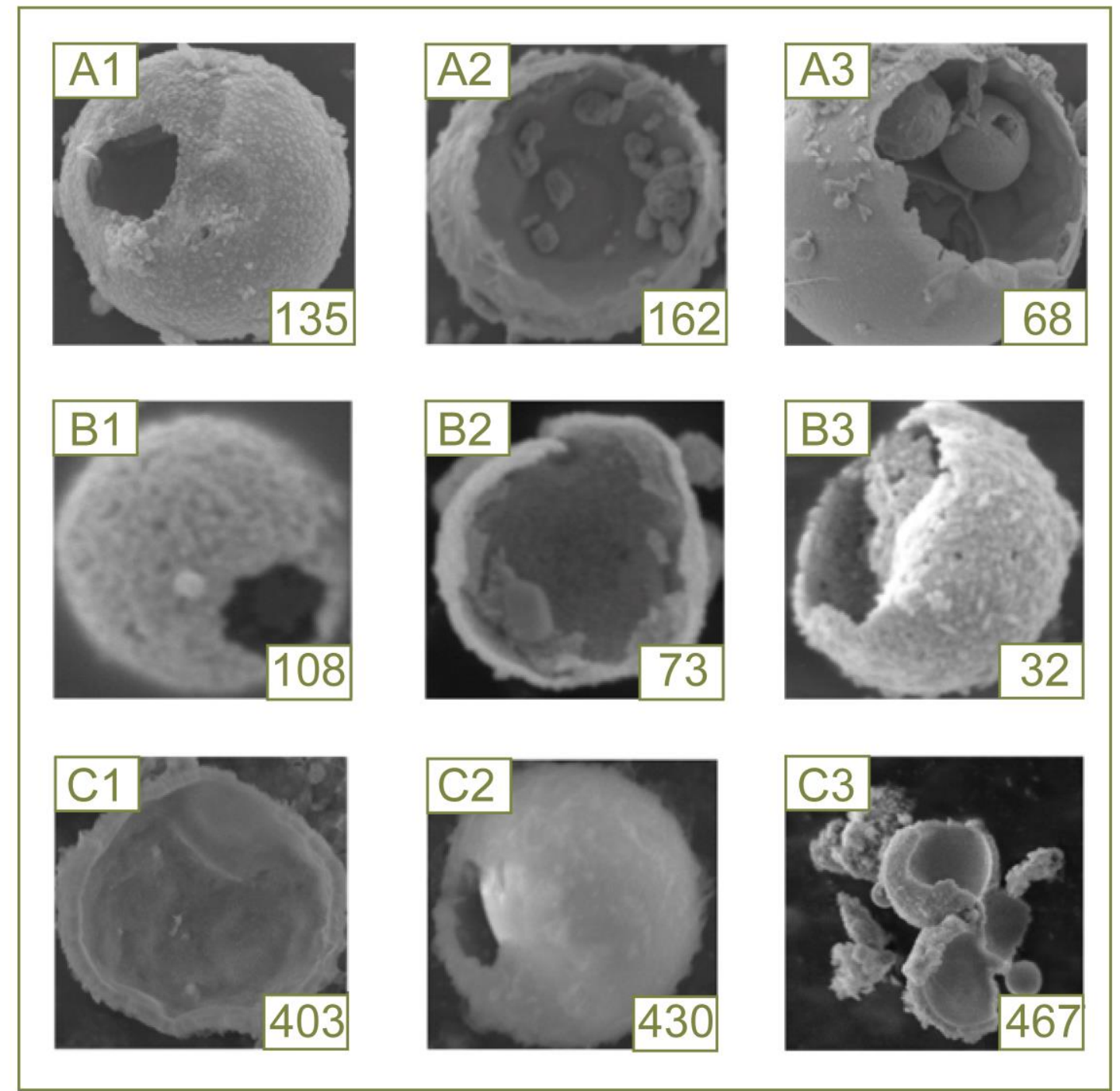

Figure S4. SEM images of destroyed capsules. Indices (A, B, C) indicating sample names correspond to Table S3. Wall sickness of the obtained capsules shown in the bottom right corner in $[\mathrm{nm}]$ 


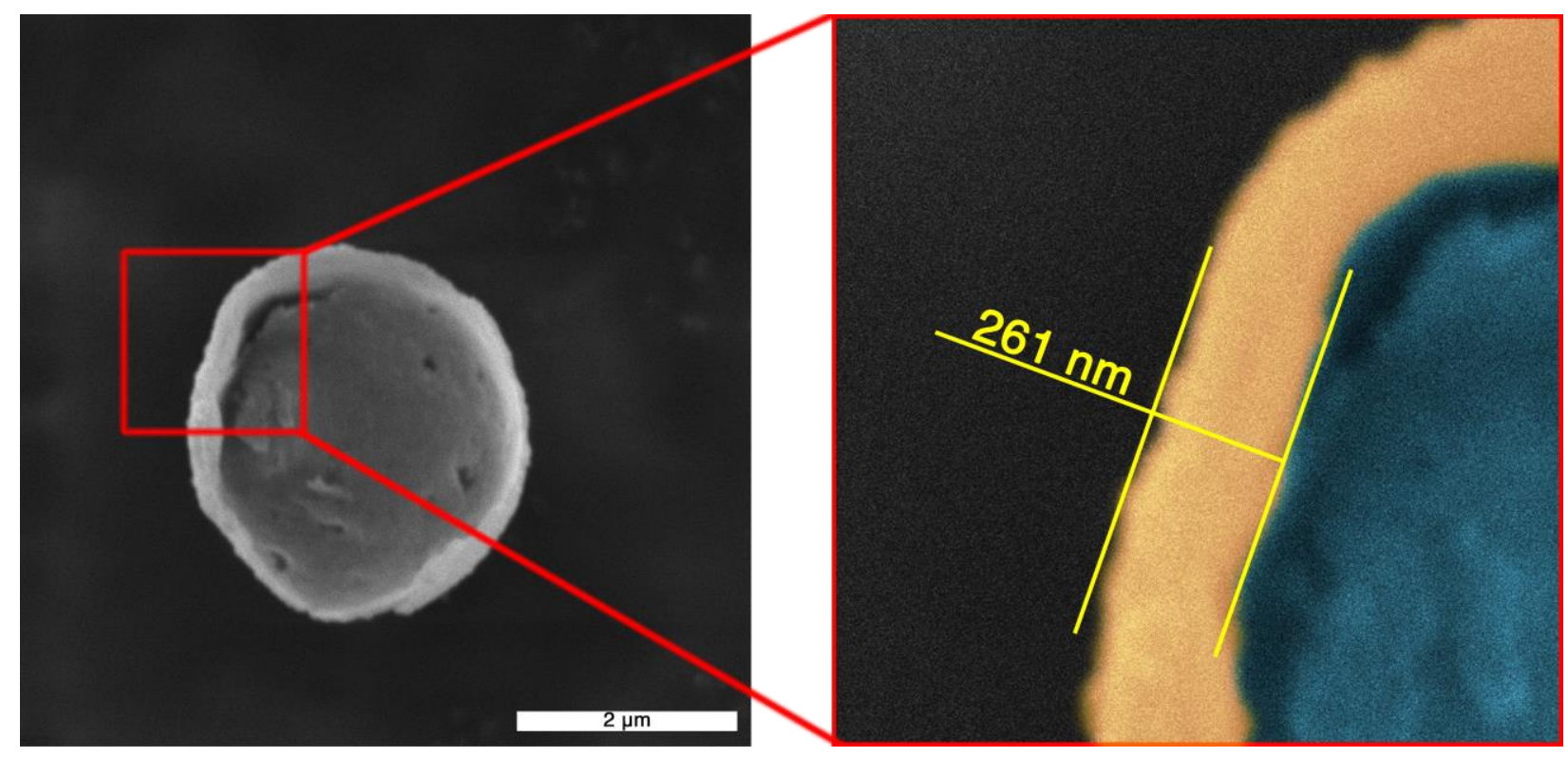

Figure S5. Wall thickness determination of the obtained capsules. On the right image shell is marked with yellow color, cavity marked with blue color
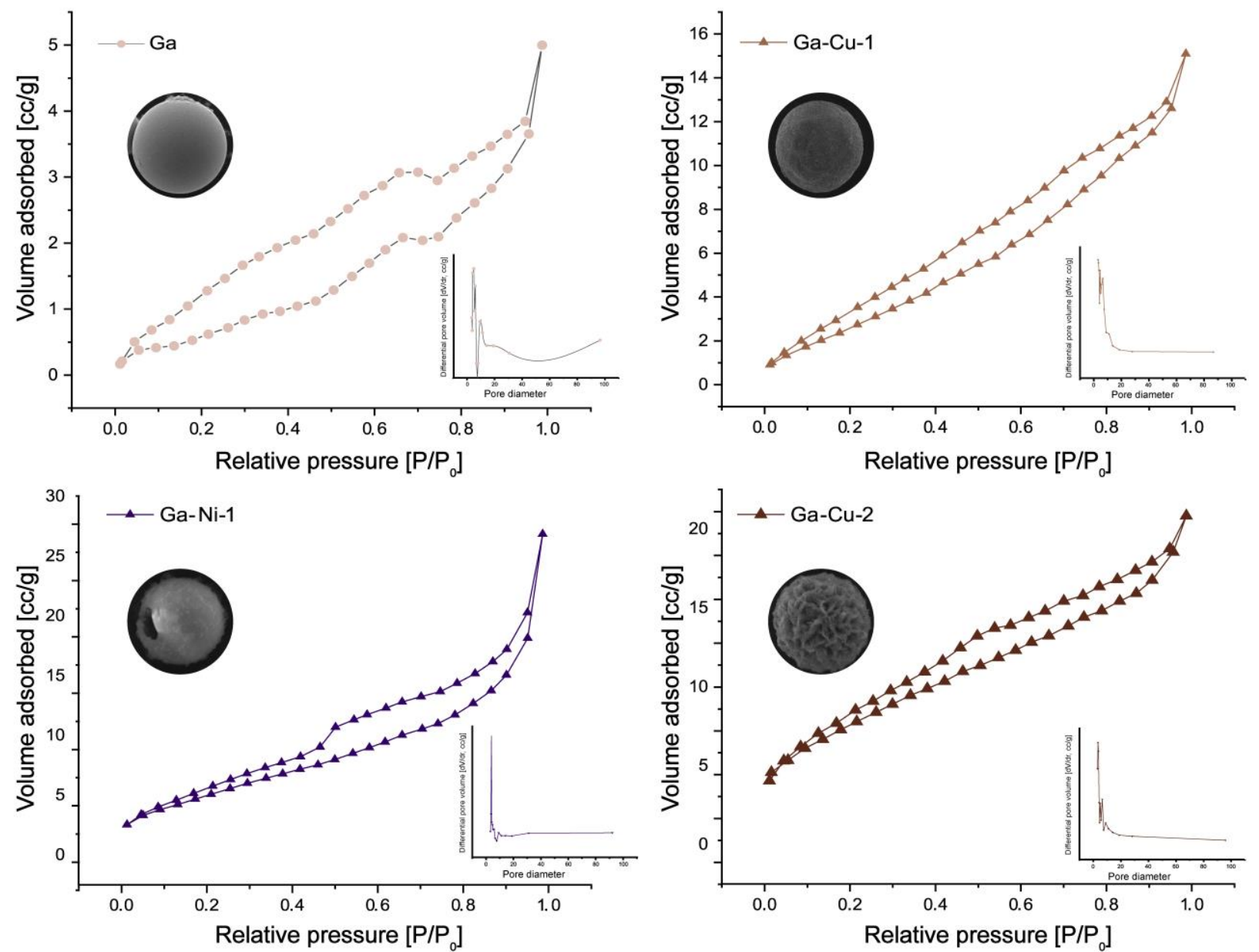

Figure S6. Nitrogen adsorption-desorption isotherms and BJH pore-size distributions of resulted capsules compared to gallium particles obtained by ultrasonication method 


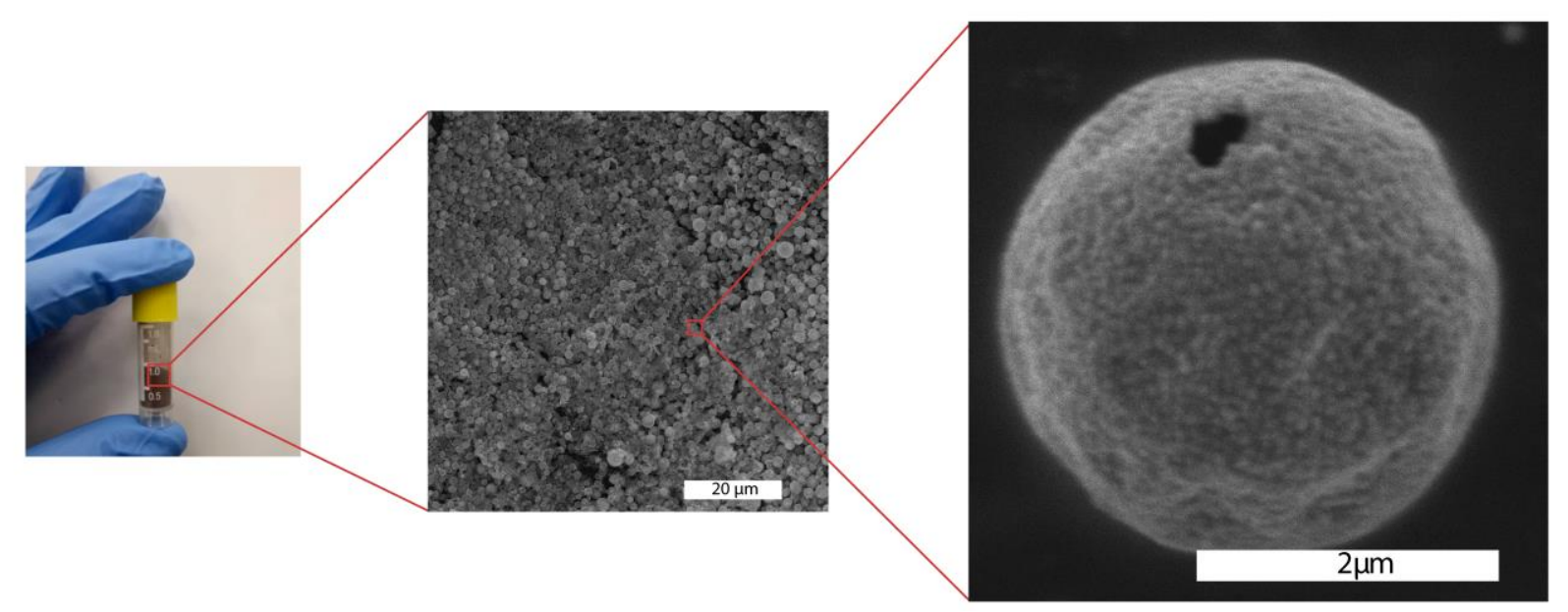

Figure S7. Large-scale production of Ga-Cu-2-PEI particles

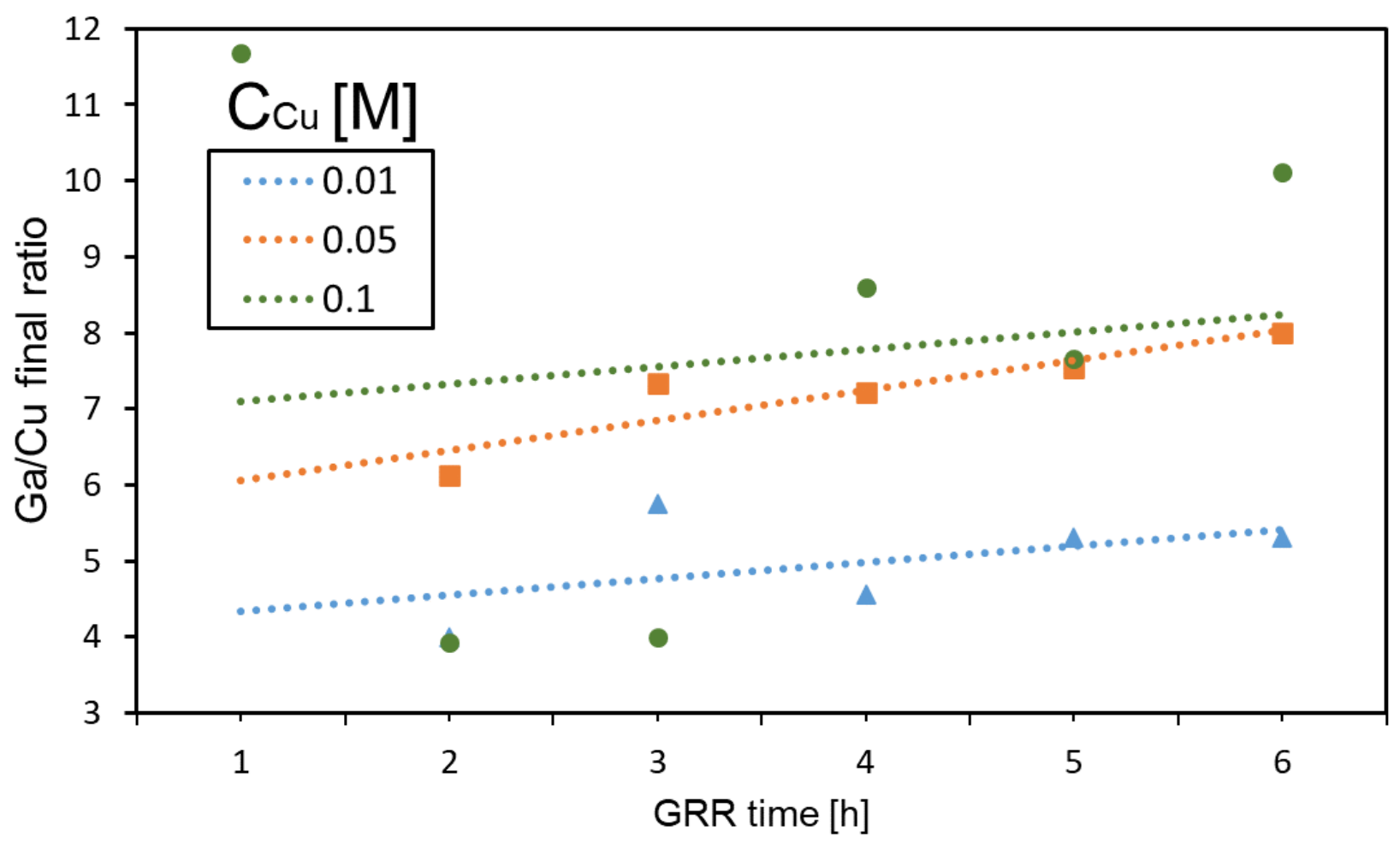

Figure S8. The ratio of $\mathrm{Ga}: \mathrm{Cu}$ in final $\mathrm{Ga}-\mathrm{Cu}-2$ capsules versus reaction time and initial concentrations of $\mathrm{Cu}(\mathrm{Ac})_{2}$ 

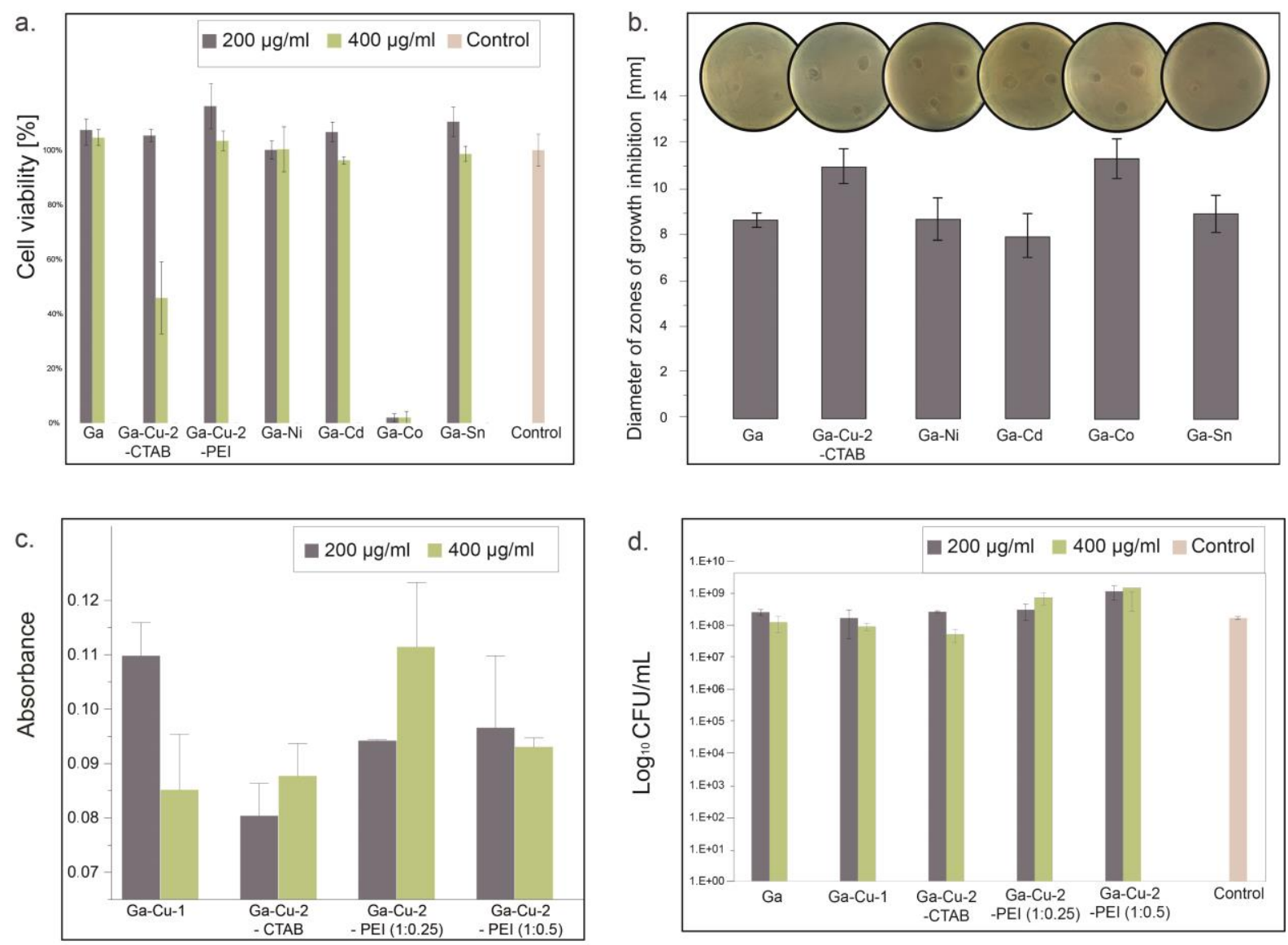

Figure S9. a) Antibacterial activity of capsules against Escherichia coli is measured via the turbidity method; b) Antibacterial activity of different capsules against Escherichia coli Nova Blue $\mathrm{Tc}^{\mathrm{R}} \mathrm{pBad} \mathrm{Amp}^{\mathrm{R}}$ strain via agar diffusion test. Zones of inhibition created in agar by the capsules shown above corresponding columns; c) $\mathrm{Cu}^{2+}$ release data of $\mathrm{Ga}-\mathrm{Cu}$ particles of different composition and morphologies; d) CFU (colony-forming units) count after incubation with different particles. All data presented are mean values \pm standard deviation of three independent experiments. 